\title{
Combined Grazing and Drought Stress Alter the Outcome of Nurse: Beneficiary Interactions in a Semi-arid Ecosystem
}

\author{
Mart Verwijmeren, ${ }^{1 *} \odot$ Christian Smit, ${ }^{2}$ Susana Bautista, ${ }^{3}$ Martin J. Wassen, ${ }^{1}$ \\ and Max Rietkerk ${ }^{1}$
}

\begin{abstract}
${ }^{1}$ Environmental Sciences, Copernicus Institute of Sustainable Development, Utrecht University, Heidelberglaan 2, P.O. Box 80115, 3508 TC Utrecht, The Netherlands; ${ }^{2}$ Conservation Ecology Group, Groningen Institute for Evolutionary Life Sciences, University of Groningen, P.O. Box 11103, 9700 CC Groningen, The Netherlands; ${ }^{3}$ Department of Ecology and IMEM, University of Alicante, Apartado de correos 99, 03080 Alicante, Spain
\end{abstract}

\begin{abstract}
Positive interspecific plant-plant interactions in (semi-)arid ecosystems are crucial for supporting ecosystem diversity and stability, but how interactions respond to grazing combined with temporal variation in drought is poorly understood. In a semi-arid area in south-eastern Spain (Murcia region), we planted 1280 saplings of the palatable shrub Anthyllis cytisoides (beneficiary) under the canopy of the unpalatable shrub Artemisia her$b a$-alba (nurse) or in open microsites between shrub patches. We applied four grazing treatments (no grazing, low goat grazing pressure, high goat grazing pressure and rabbit grazing) and two watering treatments. Sapling height and survival were followed for two consecutive years, during which one extreme drought event occurred. We analysed how grazing, watering and their combination affected nurse effects throughout the course of the study. Grazing and the drought event, but not watering, significantly altered the nurse effects.
\end{abstract}

Received 11 July 2018; accepted 16 December 2018;

published online 4 February 2019

Author Contributions MV wrote the paper with valuable feedback provided by CS, SB, MR, MJW. Data were analysed by MV, CS, SB. The experimental set-up was designed, and fieldwork was performed by $\mathrm{MV}$, CS, SB, MR, MJW.

*Corresponding author; e-mail: M.Verwijmeren@uu.nl
Under ungrazed conditions prior to the extreme drought event, nurse effects on sapling survival were neutral, whereas they were positive at rabbitgrazed plots. At low goat grazing, sapling growth was higher under nurse shrubs than in open microsites. However, after the extreme drought event, sapling survival was higher in open microsites at ungrazed plots, whereas at rabbit-grazed plots, nurse effects shifted from positive to neutral. Our findings highlight the importance of rabbit grazing in determining the direction of plant-plant interactions in arid ecosystems. Moreover, our findings support the idea that positive plant-plant interactions may wane under the combination of high grazing and drought stress.

Key words: Anthyllis cytisoides; Artemisia herbaalba; competition; facilitation; rabbit grazing; goat grazing.

\section{ManusCRipt Highlights}

- Manipulative field experiment in which we performed controlled grazing events. 
- Rabbit grazing is an important driver of positive plant-plant interactions.

- Positive plant-plant interactions wane under the combination of high drought stress and grazing.

\section{INTRODUCTION}

Over the last two decades an increasing number of studies showed the importance of interspecific facilitation (that is, net positive interactions between plants) in structuring plant communities (for reviews see: Callaway 2007; Brooker and others 2008; Pugnaire and others 2011; He and others 2013; Michalet and Pugnaire 2016), and in recent years, the importance of interspecific facilitation for structuring ecosystems (Bruno and others 2003) and for supporting biodiversity (Michalet and others 2006, McIntire and Fajardo 2014) has been widely recognized. In arid ecosystems, positive plant-plant interactions importantly determine ecosystem stability (Kéfi and others 2007; Verwijmeren and others 2013; Xu and others 2015) and therefore it is crucial to understand how plantplant interactions may change under changing environmental conditions.

Woody shrubs in arid ecosystems often act as nurse (that is, facilitator) species by relieving abiotic stress for less stress-tolerant neighbouring plants, for example by protecting them against extreme temperatures or by increasing water or nutrient availability within their direct vicinity (Gómez-Aparicio 2008; Pugnaire and others 2011). Next to that, nurse species can lower consumer pressure (that is, grazing) by physically protecting other neighbouring species against herbivores or by concealing them, a process known as associational resistance (Hay 1986). A central question to answer is how a combination of different stressors (for example, grazing and drought) may influence the direction and strength of plant-plant interactions in arid ecosystems (He and Bertness 2014; Soliveres and others 2015).

The stress gradient hypothesis (SGH) predicts that facilitative interactions between plants become more common with an increase in abiotic stress or consumer pressure (Bertness and Callaway 1994; Callaway and Walker 1997). Many studies found support for the SGH by showing that plant-plant interactions switch from competition to facilitation with increased stress (for example, Callaway and others 2002; He and others 2013; Molina-Montenegro and others 2013). However, others proposed that under resource-driven stress (for example, aridity) nonlinear relations should be expected; that is, facilitation between plant species may wane at the extreme end of a stress gradient (Michalet 2007; Maestre and others 2009). Indeed, in arid ecosystems, observational studies showed that plant-plant interactions may shift back from facilitation to competition at sites or during periods with very low rainfall (Tielbörger and Kadmon 2000; Maestre and Cortina 2004; Armas and Pugnaire 2005; Saccone and others 2009; Butterfield and others 2016). Because of this discrepancy, there is still ongoing debate on how facilitation and competition may vary over aridity gradients (Maestre and others 2009; Michalet and others 2014). In addition, the predictions from the original SGH were falsified by studies from grazed ecosystems showing that facilitation intensity increased from low to high grazing pressure, but decreased again with very high grazing pressure (Smit and others 2007; Graff and Aguiar 2011; Saiz and Alados 2012). This was because at very high grazing pressure nurse plants themselves got damaged by grazing or trampling (Michalet and others 2014), or because herbivores started searching more intensively for resources, effectively removing the protective effects of the nurse plant (Soliveres and others 2011). Adding consumer pressure to drought stress may thus possibly act as an accelerator in the waning of positive interactions at the extreme end of an aridity gradient (Verwijmeren and others 2013).

Studies investigating the combined effect of grazing and drought on plant-plant interactions in arid ecosystems are scarce (but see, Soliveres and others 2011; Verwijmeren and others 2014; Noumi and others 2016; Holthuijzen and Veblen 2016). Moreover, previous results from these studies are not consistent. For example, Soliveres and others (2011) showed that rabbit grazing altered plantplant interactions throughout the year, with positive interactions between the bunch grass Stipa tenacissima and saplings of the shrub Retama sphaerocarpa during winter and autumn. The interactions shifted to neutral in summer, as rabbits grazed more intensively during dry summer conditions when food becomes scarcer. Similarly, Holthuijzen and Veblen (2016) found that positive interactions between Artemisia tridentata ssp. wyomingensis and the native perennial grass Poa secunda in low precipitation areas weakened with grazing intensity. Contradicting this finding, Noumi and others (2016) showed that competitive effects (competition for light and water) of shrubs on Acacia tortilis tree seedlings were strongest in relatively wet and ungrazed conditions, and that net competition decreased in importance with increased grazing stress. 
This was because the seedlings were too shade intolerant and drought tolerant to profit from a shading neighbour, but the seedlings did profit from grazing protection with increased herbivory, even at high drought stress.

It is thus still unclear, how grazing pressure and drought stress interact in shaping plant-plant interactions in (semi-) arid ecosystems. On the one hand, it could be expected that grazing results in increased positive plant interactions under high drought stress, as plants will have lower ability to compensate for herbivory than in less stressed conditions (Gómez-Aparicio 2008) and will depend more on a protecting neighbour. Following this reasoning, one might expect an increase in facilitation due to the combination of stressors. On the other hand, herbivores may cancel out positive plant interactions in highly drought-stressed environments as they search for food more intensively at reduced productivity during periods of high drought stress. This may result in a vanishing of positive interactions between plants due to the combination of both stressors (Smit and others 2009; Verwijmeren and others 2013; Michalet and others 2014).

In this study, we experimentally tested how grazing and drought affected the outcome of the interaction between a mature unpalatable nurse shrub (Artemisia herba-alba) and saplings of a palatable beneficiary shrub (Anthyllis cytisoides) in a semi-arid system in south-eastern Spain. We expected (1) grazing to increase facilitative interactions between the two species at moderate drought stress and (2) the interaction to shift back to neutral or competition at the combination of grazing and high drought stress, as beneficiary plants will be unable to cope with both stressors simultaneously.

\section{MeTHODS}

\section{Study Site}

We performed our study at a semi-arid field site in south-eastern Spain (Murcia region $\left.37^{\circ} 57^{\prime} 28.37^{\prime \prime} \mathrm{N}-1^{\circ} 0^{\prime} 16.14^{\prime \prime} \mathrm{W}\right)$. Average annual rainfall is $301 \mathrm{~mm}$, with on average 38 rainy days with more than $1 \mathrm{~mm}$ of precipitation annually. Highest rainfall occurs during spring and autumn, and there is an extensive dry period in summer; average rainfall in August and July is 10 and $5 \mathrm{~mm}$, respectively. Mean monthly temperature ranges from $10.1{ }^{\circ} \mathrm{C}$ in January up to $26.7^{\circ} \mathrm{C}$ in August (Agencia Estatal de Meteorología, AEMET). Altitudes in our field site range from 175 to $302 \mathrm{~m}$ above sea level. Soil texture is loamy sand. The area consists of a mixture of relatively undisturbed slopes and abandoned terraces. On the terraces, the dominant perennial vegetation consists of the shrub species Artemisia herba-alba, A. cytisoides and Salsola genistoides, and the herbaceous species Marrubium vulgare. The area has a long history of shepherded goat grazing (during winter and spring), while the European rabbit (Oryctolagus cuniculus) is the dominant native herbivore in this system.

\section{Experimental Design}

We set up a planting experiment in a blocked factorial design, with three factors: grazing (four treatments: no grazing, low goat grazing pressure, high goat grazing pressure, rabbit grazing), microsite (two treatments: open, under shrub) and watering (two treatments: watered, unwatered). As replicated blocks, we selected 4 terraces with predominant coverage by $A$. herba-alba shrubs and an overall vegetation cover of 40-60 per cent, which provided a sufficient number of nurse species patches per terrace to set up the experiment. On each selected terrace, we built fences of about 20 by $80 \mathrm{~m}$ in December 2012. We subdivided each fence into four fenced plots of about $20 \times 20 \mathrm{~m}$, each being randomly assigned to one of the four grazing treatments. At the goat grazing and the ungrazed plots, rabbits were excluded by installing iron chicken mesh of $1 \mathrm{~m}$ height (mesh size of 3-3 cm) dug into the soil until $50 \mathrm{~cm}$ depth. Only on one occasion (December 2013) rabbits broke through into two plots, and we excluded plants that were damaged by rabbits on those plots from further analysis.

On 17-19 December 2012, we planted 1280 oneyear-old saplings of $A$. cytisoides (beneficiary species) over the four terraces, distributed equally over the four grazing treatments and the two microsites $(n=40$ per grazing treatment $\mathrm{x}$ microsite combination). We chose $A$. cytisoides, a drought-deciduous shrub from the Fabacaea family, as a beneficiary species, because it is highly palatable for both goat and rabbits (personal observation). Anthyllis cytisoides was found to constitute $41 \%$ of livestock goat diet and is thus considered as highly preferred food source for goats (Barroso and others 1995). Half of the beneficiary saplings was planted underneath mature individuals of the shrub A. herba-alba shrub (nurse species), and the other half was planted in the open microsites in between shrubs. We choose mature individuals of $A$. herba-alba, a perennial woody shrub from the Asteracaea family, as a nurse species because Artemisia spp. is not preferred by 
goats and has been found to be spatially associated with $A$. cytisoides in previous studies (Haase and others 1996; Verwijmeren and others 2014). Artemisia $s p p$. is reported to be a highly unpreferred food source for goats as it only constitutes 3\% of their diet (Barroso and others 1995). We selected $A$. herba-alba nurse patches with sizes ranging from $50 \mathrm{~cm}$ to $2 \mathrm{~m}$ (measured as the maximum width of each patch), distributed evenly within a plot. Before planting, round planting holes (diameter $20 \mathrm{~cm}$, depth $20 \mathrm{~cm}$ ) were dug with a mechanical drilling device. All saplings that were planted underneath a shrub were planted north of the nurse patch underneath its canopy, $25-50 \mathrm{~cm}$ away from the nurse stem, and underneath the canopy of the mature shrub, so that branches of A. herba-alba sheltered the planted saplings. All saplings that were planted in the open were minimally at $0.5 \mathrm{~m}$ distance from the canopy of the nurse patch (or any other perennial plant species). Most of the soil underneath the canopies of Artemisia herba-alba was bare, but at some of the selected $A$. herba-alba patches we found annuals growing under or near their canopy. To remove potential competition and standardize initial conditions, we removed all annuals in the vicinity of the planting holes $(20 \mathrm{~cm}$ or closer), after the planting of the saplings. To reduce the risk of mortality due to transplant shock, we watered the plants during the first week after planting and again 33 days after planting, by pouring $1 \mathrm{l}$ of water at every planting hole. All saplings were labelled with a metal tag placed on the soil, with unique numbers. Saplings were 1 year old and were obtained from a local nursery where they were grown in turf-filled containers of $10 \mathrm{~cm}$ deep. Sapling heights were equalized before planting by cutting them at a standard height of $12 \mathrm{~cm}$ and were planted including their complete root system and the turf.

\section{Grazing Events}

In line with the normal practice of local shepherded goat grazing, we implemented grazing events only during winter and spring, outside the drought period. As A. cytisoides loses its leaves during the drought period in summer, this ensured palatability of the saplings. We randomly selected 36 lactating, mature, female goats from the herd of a local shepherd and implemented 3 grazing events: 14 May 2013, 31 January 2014 and 1 May 2014. For the low goat grazing pressure treatment, 3 adult goats were placed inside the enclosures, whereas for the high goat grazing pressure treatment 6 adult goats were placed within the enclosures. Goats were left in the enclosure from 10:00 until 17:00. These grazing events mimicked relatively low $(0.41$ animals ha ${ }^{-1} \mathrm{y}^{-1}$ ) and high (0.82 animals ha ${ }^{-1} \mathrm{y}^{-1}$ ) grazing pressures. The rabbit plots were not grazed by goats during the course of the experiment. To check for rabbit presence in the four rabbit plots, we qualitatively assessed rabbit density by counting active latrine (with fresh droppings/pellets) numbers on each plot. We defined a latrine as an accumulation of 20 or more pellets on a surface of $20 \times 30 \mathrm{~cm}$ (Virgós and others 2003). Latrine abundance has been shown to be correlated with rabbit densities in Mediterranean scrublands (Virgós and others 2003; Calvete and others 2006). We found rabbit latrines on all four plots, ranging from 0.015 latrines per square metre to 0.019 latrines per square metre, which indicates a moderately low rabbit density (Virgós and others 2003), in agreement with recent values estimated for southern Spain (Guerrero-Casado and others 2016a, b).

\section{Drought Event and Watering Treatment}

During the approximately 2 years that we ran the experiment (Jan 2013 till October 2014), a total of $375.1 \mathrm{~mm}$ of rainfall was recorded by a nearby rainfall gauge from the SIAM (Sistema de Información Agrario de Murcia), weather station MU52. In 2014, from January until September, an extreme drought event occurred in which only $47.3 \mathrm{~mm}$ of rainfall was recorded, whereas average precipitation for this period is $168 \mathrm{~mm}$, based on monthly average rainfall from 1981 until 2010 (AEMET). This extended drought period enabled us to study the effect of an extreme drought event along with our grazing and watering treatments.

Combined with natural variability in rainfall over time, we experimentally mimicked rainfall events by watering half of the plants at three moments in time during our experiment. Plants to be watered were randomly selected with equal numbers for each grazing treatment, microsite and block combination. We watered them by pouring $1.5 \mathrm{l}$ of water in the planting hole. As the planting hole makes a slight depression, this ensured the water to infiltrate in the plant's vicinity, thereby mimicking a rainfall event of about $12 \mathrm{~mm}$. We watered plants at evenings to decrease direct evaporation. We repeated the watering at three events (25-28 July 2013, 13-16 April 2014 and 1-4 May 2014). These dates were chosen to simulate a shortening of the dry season, being chosen at the start or end of the dry season. To test the effect of the watering events 
we measured relative water content (RWC) from ten harvested leaves of 128 A. cytisoides saplings (distributed evenly over the microsites) before watering the saplings and at three days after the watering event took place in May 2014. RWC of harvested leaves prior to the watering ranged from 30 to $45 \%$, without significant differences between the microsites. After watering we measured RWC values ranging from 60 to $75 \%$, again without significant differences between the microsites.

\section{Sapling Measurements}

We surveyed the saplings on the following dates throughout 2013 and 2014: 21 January, 7 March, 22 April, 15 May, 20 January, 1 February, 23 April, 2 May and 6 October, covering seedling establishment, seedling performance before and after grazing events and potential seedling regrowth after the severe drought. As the primary fitness measure at every survey we recorded sapling survival. Saplings were considered dead if they had a brownish colour under their bark and did not resprout during later measurements in the course of the experiment. As a secondary fitness measure, we measured sapling height before and after every grazing event to assess the direct impact of goats. To obtain a nondestructive measure for the ability of the saplings to resprout after the first rains $(75.5 \mathrm{~mm} 22-24$ September 2014) after the extreme drought event, we harvested all fresh leaves of the saplings that were still alive at the final survey (6 October 2014). After sampling, leaves were oven-dried at $60^{\circ} \mathrm{C}$ for $48 \mathrm{~h}$ and weighed to determine the dry weight leaf biomass.

\section{Soil Moisture Measurements}

To compare the two microsites (open, under shrub) in their effect on soil moisture after rainfall events, we measured soil water content using time domain reflectometry (TDR). TDR probes of $20 \mathrm{~cm}$ long were installed in the planting holes, 5 centimetres apart from the stem of $A$. cytisoides saplings, at twelve points per plot (six under a shrub and six at the open microsite). Following a single rainfall event of $10.2 \mathrm{~mm}$ on 28 February 2013, we measured soil moisture on the 1st, 7th and 27th of March 2013, which allowed investigating the differential drying between the two microsites. Additionally, we measured soil moisture on 5 May 2013 (after two rainfall events of $27 \mathrm{~mm}$ and $24 \mathrm{~mm}$ on the 27th and 28th of April 2013) and on 1 October 2014 (after two rainfall events of 61.5 and 7.7 on the 22nd and 29th of September 2014).

\section{Data Analysis}

We calculated relative height by $\ln \left(\right.$ Height $\left._{\text {end }}\right)-$ $\ln \left(\right.$ Height $\left._{\text {start }}\right)$ as recommended by Paine and others (2012) for cases where only one life stage of relative growth is modelled. We performed general(ized) linear mixed effect models depending on the data distribution of the response variable (Zuur 2009). For survival data we ran a generalized linear mixed effect model with binominal distribution and logit link. For height data we ran a general linear mixed effect model and only included plants that survived until the last measurement round. For both the survival data and the height data, we used two measurements in time, May 2014 (pre-drought) and October 2014 (post-drought), and regarded these as repeated measures, subsequently indicated by 'drought event' (pre-drought and post-drought). We choose these two moments in time to explore the effect of the extreme drought event over time on the overall mortality during the summer months. To analyse the effects of grazing, watering, microsite and the drought event on the survival or the relative height, we ran general(ized) linear models with the factor grazing within terrace and plant-ID as random factors (lme 4 package, Bates and others 2015). We ran models with the factors grazing, watering, microsite and drought event and their interactions as the main fixed effects. To check for contrasts between microsites per grazing treatment we ran separate models for each grazing treatment-drought event combination, again with terrace as a random blocking factor, and applied a Bonferroni correction on the $\mathrm{p}$ values. For the height data we did not include rabbit plots as survival (and thus observation nr.) was very low on these plots. Data on leaf biomass were analysed using a generalized linear model with a gamma distribution and a log link. For soil moisture content data, we ran a general linear model with only microsite as a fixed effect, as we found no effects of grazing. As we performed three soil moisture measurements after the single rainfall event in March 2013, we regarded the three measurement moments in March as repeated measurements by adding plant-ID as an extra variable in the random error structure and by adding time as a fixed factor. All analyses were performed in R 3.2.3 (R Core Team 2015).

\section{Results \\ Survival}

Overall, we found significant effects of grazing treatment and drought event on survival of sap- 
lings, and a significant interaction between grazing treatment and microsite, as well as a significant interaction between grazing treatment and drought event (Table 1). The watering treatment did not have any significant effect on sapling survival either alone or in interactions with other factors. Before the drought period we found equal survival rates for the ungrazed, low goat grazing and high goat grazing plots, but lower survival rates for the rabbit-grazed plots (Figure 1). During the drought event sapling survival dropped in all four plots, but less on the low goat grazing plots compared to the other three grazing treatments. Post hoc comparison for pairwise contrasts between microsites within the four grazing treatments showed that in May 2014, survival rates were not significantly different between the two microsites for no grazing $\left(\chi_{1,191}^{2}=0.116, p=0.732\right)$, low goat grazing $\left(\chi_{1}\right.$, $\left.257^{2}=0.249, p=0.617\right)$ and high goat grazing plots $\left(\chi_{1,285}^{2}=0.007, p=0.932\right)$. For rabbit-grazed plots however, sapling survival was significantly lower in the open microsite compared to under shrubs $\left(\chi_{1,323}^{2}=16.826, p<0.001\right)$. In October 2014, pairwise contrasts showed no significant differences between the two microsites for the low goat grazing plots $\left(\chi_{1,257}^{2}=0.393, p=0.530\right)$, high goat grazing plots $\left(\chi_{1,285}^{2}=0.162, p=0.684\right)$ and rabbit grazing plots $\left(\chi_{1}^{2}, 323=0.178, p=0.184\right)$. On the ungrazed plots, however, we found a significant lower sapling survival under shrubs $\left(\chi_{1}\right.$, $\left.191^{2}=5.74, p=0.016\right)$.

\section{Relative Height}

Overall, we found significant effects of grazing treatment, microsite and drought event on the relative sapling height (Table 2). Again, our watering treatment did not significantly affect the relative sapling height either alone or in interactions. In May 2014 (Figure 2, upper panel), for the ungrazed plots, relative height was not different between the two microsites $\left(F_{1,61}=1.478\right.$, $p=0.456)$. For low goat grazing, however, relative height was significantly higher under shrubs than in the open $\left(F_{1,140}=8.2811, p=0.008\right)$. For high goat grazing we similarly found significantly higher saplings under shrubs $\left(F_{1,81}=4.861, p=0.030\right)$. At the final measurement in October 2014, after the severe drought (Figure 2, lower panel) for ungrazed plots, saplings in both microsites had equal relative height $\left(F_{1,61}=2.842, p=0.192\right)$. For low goat grazing we found significantly higher relative sapling height under shrubs $\left(F_{1,140}=6.086\right.$, $p=0.031$ ), but for high goat grazing we found equal relative sapling height in the two microsites $\left(F_{1,81}=3.378, p=0.280\right)$.

\section{Leaf Biomass}

Leaf biomass was significantly affected by grazing treatment and microsite, with decreasing leaf biomass from no grazing to high goat grazing, and higher leaf biomass for saplings growing in the open microsite (Table 3, Figure 3).

Table 1. Summary Statistics of Generalized Linear Mixed Effect Model with Binomial Distributions for Survival Data

\begin{tabular}{lrrr}
\hline Factor & $\chi^{2}$ value & df & $p$ value \\
\hline Grazing & $\mathbf{1 5 . 4 3 8}$ & $\mathbf{3}$ & $\mathbf{0 . 0 0 1}$ \\
Microsite & 0.858 & 1 & 0.354 \\
Watering & 3.053 & 1 & 0.080 \\
Drought event & $\mathbf{9 5 . 1 7 8}$ & $\mathbf{1}$ & $\mathbf{0 . 0 0 1}$ \\
Grazing:Microsite & $\mathbf{9 . 7 1 8}$ & $\mathbf{3}$ & $\mathbf{0 . 0 2 1}$ \\
Grazing:Watering & 2.515 & 3 & 0.472 \\
Microsite:Watering & 0.002 & 1 & 0.964 \\
Grazing:Drought event & $\mathbf{1 1 . 0 6 3}$ & $\mathbf{3}$ & $\mathbf{0 . 0 1 1}$ \\
Microsite:Drought event & 3.059 & 1 & 0.080 \\
Watering:Drought event & 3.217 & 1 & 0.072 \\
Grazing:Microsite:Watering & 2.713 & 3 & 0.437 \\
Grazing:Microsite:Drought event & 2.253 & 3 & 0.521 \\
Grazing:Watering:Drought event & 1.228 & 3 & 0.746 \\
Microsite:Watering:Drought event & 0.031 & 1 & 0.860 \\
Grazing:Microsite:Watering:Drought event & 1.248 & 3 & 0.741
\end{tabular}




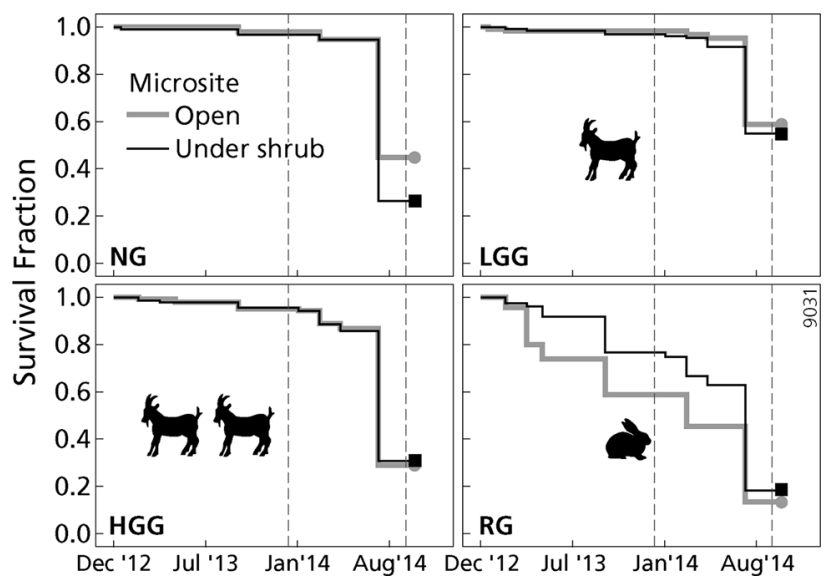

Figure 1. Survival fraction of planted saplings over time over the two microsites and the four grazing treatments. $N G=$ no grazing, $L G G=$ low goat grazing pressure, $H G G=$ high goat grazing pressure, $R G=$ rabbit grazing. The period in between the two vertical dashed lines indicated the prolonged drought period.

Table 2. Summary Statistics of General Linear Mixed Effect Model with Normal Distribution for Relative Height Data for May 2014 and October 2014

\begin{tabular}{lrrr}
\hline Factor & $\mathrm{df}_{\text {num }}: \mathrm{df}_{\text {den }}$ & $F$ value & $p$ value \\
\hline Grazing & $\mathbf{2 : 6}$ & $\mathbf{9 . 0 2 8}$ & $\mathbf{0 . 0 1 8}$ \\
Microsite & $\mathbf{1 : 2 8 1}$ & $\mathbf{1 1 . 1 1 5}$ & $\mathbf{0 . 0 0 1}$ \\
Watering & $1: 281$ & 0.354 & 0.552 \\
Drought event & $\mathbf{1 : 2 8 5}$ & $\mathbf{1 8 . 4 7 7}$ & $\mathbf{0 . 0 0 0}$ \\
Grazing:Microsite & $2: 281$ & 0.268 & 0.765 \\
Grazing:Watering & $2: 281$ & 1.348 & 0.262 \\
Microsite:Watering & $1: 281$ & 0.209 & 0.648 \\
Grazing:Drought event & $2: 285$ & 1.327 & 0.267 \\
Microsite:Drought event & $1: 285$ & 0.106 & 0.745 \\
Watering:Drought event & $1: 285$ & 0.274 & 0.601 \\
Grazing:Microsite:Watering & $2: 281$ & 1.852 & 0.159 \\
Grazing:Microsite:Drought event & $2: 285$ & 1.009 & 0.366 \\
Grazing:Watering:Drought event & $2: 285$ & 0.691 & 0.502 \\
Microsite:Watering:Drought event & $1: 285$ & 0.815 & 0.367 \\
Grazing:Microsite:Watering:Drought event & $2: 285$ & 0.780 & 0.459 \\
& & & \\
Significant factors are indicated in bold. & & & \\
\hline
\end{tabular}

\section{Soil Moisture Measurements}

After a rainfall event of $10.2 \mathrm{~mm}$ in March 2013, we found significantly higher soil moisture in the open than in the shrub microsite (Table 4, Figure 4 first three pairs) and a significant interaction between microsite and time, indicating a decrease in the difference between the two microsites over time. After rainfall events of $27 \mathrm{~mm}$ and $24 \mathrm{~mm}$ in May 2013 soil moisture was no longer different between the two microsites (Table 4, Figure 4). In October 2014, after rainfall events of 61.5 and $7.7 \mathrm{~mm}$, we found the opposite: soil moisture was higher under the shrub than in the open (Table 4, Figure 4).

\section{Discussion}

The aim of this study was to assess how plant-plant interactions shift under a combination of different grazing treatments and drought stress. We found contrasting responses to the grazing treatments before and after the extreme drought event, while our watering treatment did not have any significant effects on sapling survival and height. Watering effects were likely to operate only at a short term and were overridden by the effects of the extreme drought event and grazing treatments at the longer term, which is in line with (Metz and Tielbörger 2016). Before the drought event we found neutral nurse effects on the beneficiary at 


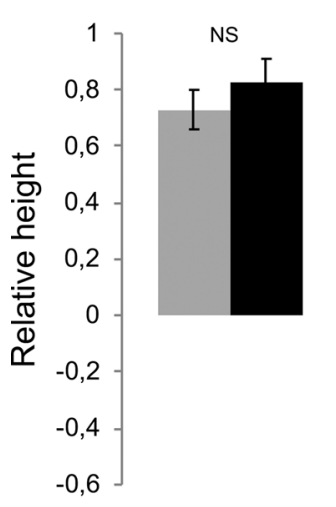

May 2014
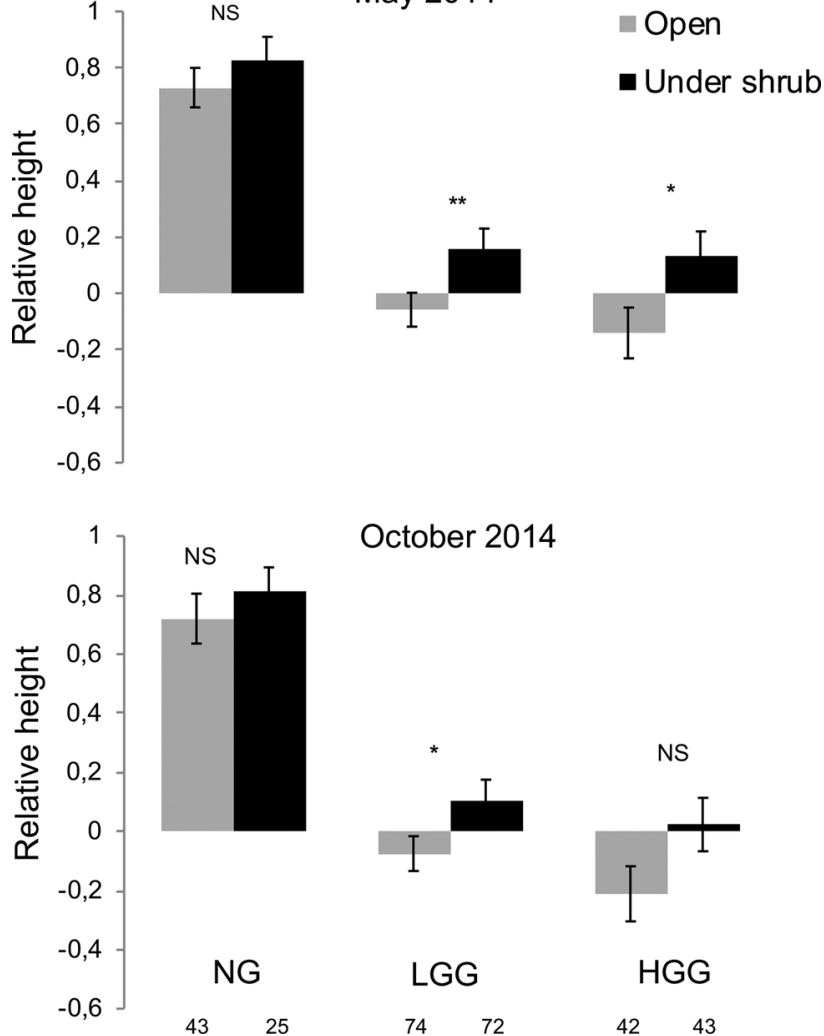

October 2014
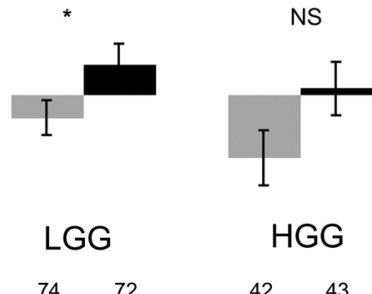

Figure 2. Relative height over the two microsites and the four grazing treatments before the severe drought in May 2014 (upper panel) and after the severe drought in October 2014 (lower panel). $N G=$ no grazing, $L G G=$ low goat grazing pressure, $H G G=$ high goat grazing pressure. * and ** indicate a significant difference at $p<0.05$ and $p<0.01$, resp., between the two microsites. The numbers below the bars at the lower panel indicate the number of observations per treatment level.

Table 3. Summary Statistics of Generalized Linear Mixed Effect Models with Gamma Distribution for Leaf Biomass

\begin{tabular}{llrl}
\hline Factor & df & $\chi^{2}$ value & $p$ value \\
\hline Grazing & $\mathbf{3}$ & $\mathbf{7 . 3 0 1}$ & $\mathbf{0 . 0 2 6}$ \\
Microsite & $\mathbf{1}$ & $\mathbf{2 3 . 0 0 3}$ & $\mathbf{0 . 0 0 0}$ \\
Watering & 1 & 3.304 & 0.069 \\
Grazing:Microsite & 3 & 1.558 & 0.212 \\
Watering:Microsite & 1 & 2.709 & 0.258 \\
Grazing:Watering & 3 & 1.067 & 0.586
\end{tabular}

Significant factors are indicated in bold.

ungrazed plots (equal survival and height of saplings in the two microsites), but this swapped to competitive effects after the drought event (lower sapling survival at the nurse microsite). Before the drought event, rabbit grazing resulted in higher sapling survival under the nurse shrubs, and low goat grazing resulted in relatively higher sapling

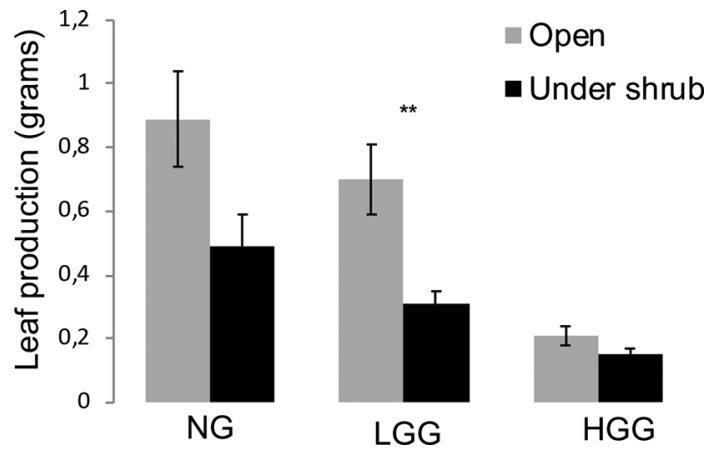

Figure 3. Dry weight biomass of leaves per sapling for the two microsites and three grazing treatments. ** indicates a significant difference at $p<0.01$.

growth under shrubs than in the open. This shows that associational resistance is still an important process at moderate drought stress. However, these positive effects waned after the extreme drought event. This suggests that a combination of stressors may result in disappearance of positive effects, 
Table 4. Summary Statistics of General Linear Mixed Effect Models with Normal Distribution for Volumetric Water Content at Three Moments in Time

\begin{tabular}{llllll}
\hline & Factor & $\mathrm{df}$ nom. & $\mathrm{df}_{\text {denom. }}$ & $F$ value & $p$ value \\
\hline March 2013 & Microsite & $\mathbf{1}$ & $\mathbf{2 2 7}$ & $\mathbf{3 0 . 6 1 8}$ & $<\mathbf{0 . 0 0 1}$ \\
& Time & $\mathbf{1}$ & $\mathbf{2 4 7}$ & $\mathbf{3 6 4 3 . 6 2 8}$ & $<\mathbf{0 . 0 0 1}$ \\
& Microsite:Time & $\mathbf{1}$ & $\mathbf{2 4 8}$ & $\mathbf{2 9 . 7 6 0}$ & $<.001$ \\
May 2013 & Microsite & 1 & 210 & 2.354 & 0.126 \\
Oct 2014 & Microsite & $\mathbf{1}$ & $\mathbf{1 7 5}$ & $\mathbf{2 5 . 0 6 7}$ & $\mathbf{0 . 0 0 1}$
\end{tabular}

Significant factors are indicated in bold.

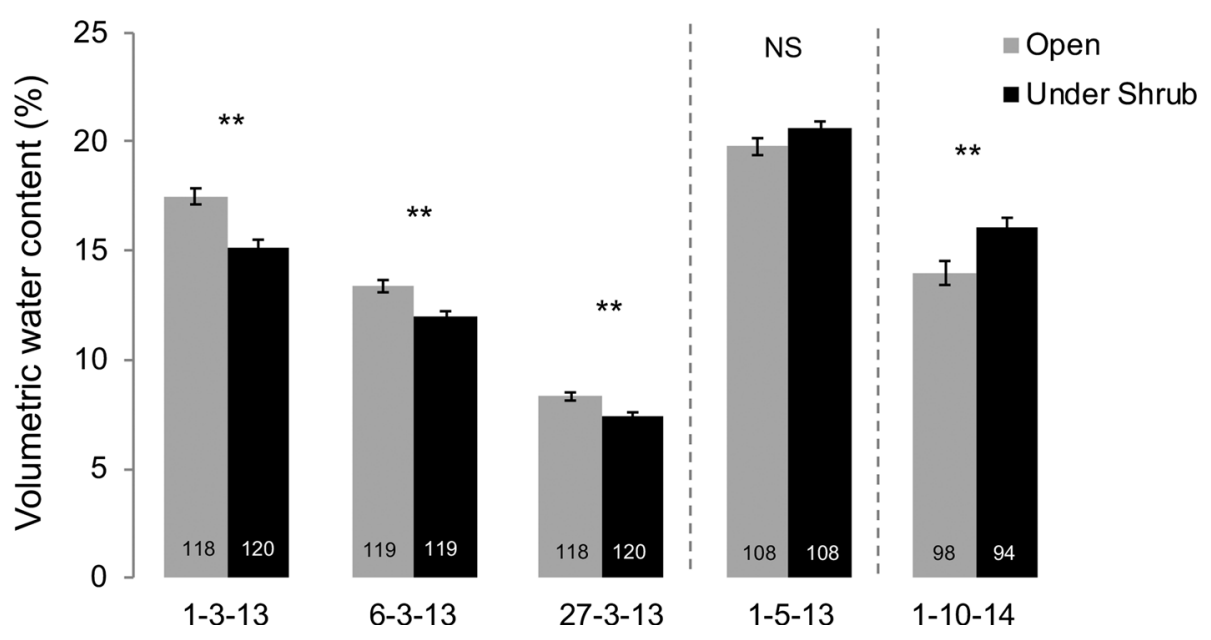

Figure 4. Volumetric water content at five moments in time. The first three measurements are treated as repeated measures after a rainfall event of $10.2 \mathrm{~mm}$ at 28 February 2013. Soil moisture at 1-5-13 was measured after rainfall events of $27 \mathrm{~mm}$ and $24 \mathrm{~mm}$ at 27th and 28th April 2013, respectively. Soil moisture at 1-10-14 was measured after a rainfall event of $61.5 \mathrm{~mm}$ at 22 September and $7.7 \mathrm{~mm}$ at 29 September 2014 . ** indicates a significant difference at $p<0.01 . \mathrm{NS}$ indicates nonsignificance. The numbers within bars indicate the number of observations per treatment level.

confirming recent observations along a combined drought stress and mowing disturbance gradient (Le Bagousse-Pinguet and others 2014). In addition, our findings reinforce the little empirical evidence to date that in semi-arid ecosystems associational resistance may be a more important mechanism resulting in positive plant-plant interactions than microhabitat amelioration (Louthan and others 2014; Perea and Gil 2014; Tálamo and others 2015).

\section{Nurse Effects Under Ungrazed Conditions}

At the ungrazed plots, and before the drought event occurred, we found neutral nurse effects (no difference between open microsites and shrub microsites) on beneficiary survival and height. This neutral effect can be explained by the contrasting results we found for soil moisture: higher soil moisture in the open microsite after a low rainfall event, equal soil moisture between the two microsites after moderate rainfall and higher soil moisture under shrubs after a heavy rainfall. During dry conditions or at very low rainfall events, soil moisture might be slightly lower under a shrub canopy, due to rainwater interception by the nurse canopy (Tielbörger and Kadmon 2000) and due to water uptake by the nurse plant, resulting in lower water availability for saplings growing under the shrub (and thus relative better sapling performance in the open). However, after relatively high rainfall amounts, soil moisture can be higher under shrubs due to enhanced water infiltration (Mayor and others 2009), resulting in higher sapling performance in this microsite. Considering the resprouting response to the first rains after the extreme drought event, our results showed that leaf biomass 
was higher in the open microsite. Hence, even if high rainfall results in higher soil moisture in the shrub microsite, this positive effect might be partly counteracted by other factors such as increased light availability in the open microsite. These shortterm trade-offs from single climatic extremes leading to shifts from competition to facilitation have also been observed by Grant and others (2014), who found species-specific shifts in grassland species in response to extreme weather events.

At the ungrazed plots, the extreme drought event resulted in a shift from neutral nurse effects towards negative effects, with higher final sapling survival in the open microsite. Although an increase in positive interactions is predicted by the SGH (Callaway and Walker 1997; Brooker and Callaghan 1998) and recent meta-analysis (He and others 2013), we thus found opposing patterns with an increase in competition at extreme drought stress. We propose that rainwater interception by the nurse canopy under extreme low rainfall is one likely explanation for the better performance of saplings in the open microsite; we recorded several rainfall events during the drought period of less than $2 \mathrm{~mm}$ which offer little opportunity for stem flow and through fall under nurse plants but can be critical inputs in open microsites. Our volumetric soil moisture measurements showed that at these low rainfall events, higher soil moisture in the open microsite can be expected. Our observation is in line with previous studies from semi-arid ecosystems that showed that at the dry end of an aridity gradient, or during extended drought periods, negative interactions between plants may prevail (Tielbörger and Kadmon 2000; Maestre and Cortina 2004; Castanho and others 2015; Butterfield and others 2016). These and our results fit the notion that along resource-driven stress gradients facilitation is only expected under intermediate stress as only then the positive effects of neighbours exceed their negative effects (Maestre and others 2009; Holmgren and Scheffer 2010).

\section{Nurse Effects Under Goat and Rabbit Grazing}

Rabbit grazing led to higher sapling mortality than goat grazing. Overall, before the drought event occurred, goat grazing did not result in differential survival rates between the two microsites, indicating neutral effects of the nurse on the beneficiary. Rabbit grazing did however result in a significant decrease in sapling survival, with a higher survival rate of saplings under shrubs, indicating facilitative effects by the nurse shrubs. This difference between goat and rabbit treatments can be explained by the browsing behaviour of goats and rabbits. Goats only partly browsed the fresh shoots, while rabbit grazing resulted in removal of all the aboveground biomass (personal observation), therefore having a bigger impact on survival. This result shows that rabbits can have a bigger inhibiting role on recruitment of shrubs than larger herbivores as goats, which is in agreement with studies from temperate ecosystems where rabbits rather than cattle were the limiting factor for clonal shrub expansion (Smit and others 2010). As rabbits are not physically hindered to enter nurse patches, it is most likely that the higher survival under shrubs is caused by concealment of the sapling, as also observed by Louthan and others (2014). We found an 18 per cent higher survival of saplings under shrubs on rabbit plots. This is in line with a previous study in a semi-arid system that found a $22 \%$ higher survival of saplings of Retama sphaerocarpa protected by the perennial tussock grass Stipa tenacissima two months after initializing the experiment (Soliveres and others 2011). These and our results confirm that both shrubs and tussock grasses can be effective nurse species under moderate drought stress (before the drought event occurred) in combination with grazing by rabbits. We do however note that higher densities of wild ungulates compared to our controlled grazing events, may lead to increased consumption of Artemisia herba-alba shrubs, possibly leading to the disappearance of grazing protection effects, especially during periods of extended food shortages when wild herbivores may shift to browsing less preferred food sources.

For both low and high goat grazing, saplings under shrubs got higher than saplings in open microsites. This confirmed the hypothesis that grazing can enhance positive interactions under drought conditions and that protection from grazing may be a more important facilitation mechanism than microhabitat amelioration. This is in line with Louthan and others (2014) who showed that beneficiary forb concealment by nurse shrubs is a more important driver of facilitative interactions than microhabitat amelioration in African savannahs. In our study, the positive effect of shrubs on relative sapling height was highest at low goat grazing. This is consistent with other studies that showed that plant-plant interactions can shift from neutral to positive when changing from ungrazed to grazed conditions (Brooker and others 2006; Graff and others 2007).

After the extreme drought event, the nurse effect on the sapling survival at the rabbit-grazed plots shifted from positive to neutral. A review by Mi- 
chalet and others (2014) proposed two possible mechanisms for a decline in facilitation at the extreme end of environmental severity gradients, either a decrease in the functioning of the protecting nurse shrub under a disturbance (for example, grazing) gradient or an increase in competition for resources under extreme resource-driven stress (for example, drought). As in our case both grazing pressure and drought are interacting, it is hard to distinguish these potential explanations. We suggest that for the rabbit grazing plots, a combination of both competition for water and a decrease in protective effects could explain the shift in interaction, as the nurse species lost most of its leaves during the extreme drought period, resulting in decreased concealment of the saplings under their canopy.

\section{SYNTHESIS}

Overall, our results show that low-intensity goat grazing can result in a shift from neutral to positive plant-plant interactions under drought stress. Moreover, our results show the potentially large impacts of rabbit grazing on plant-plant interactions. So far, most studies on plant-plant interactions in arid ecosystems that include grazing focussed on the effects of larger herbivores, such as sheep and goats (for example, Saiz and Alados 2011; Perea and Gil 2014; Filazzola and others 2018). Also, we showed that an extreme drought event can result in increased competitive interactions between plants at ungrazed conditions, while a combination of severe drought and herbivory can result in a waning of positive plant-plant interactions. These findings support recent theoretical frameworks predicting that a combination of stressors might result in the waning of positive interactions (Verwijmeren and others 2013; Michalet and others 2014), which may lead to more rapid degradation of arid ecosystems than would be expected when assuming increased positive interactions with increasing environmental severity. As seedling and sapling survival is a critical stage in the life cycle of dryland plants, and because woody shrubs are considered important nurse plants for seedling and sapling survival (Bonanomi and others 2011; Pugnaire and others 2011), a decrease in positive interactions may lead to a lack of recruitment and hard-to-reverse degradation of arid ecosystems. Our finding that facilitation wanes after an extreme drought event may thus have important implications for the management of arid ecosystems: it suggests that restoration measures using nurse species may not be successful if extreme drought periods will increase in frequency.

\section{ACKNOWLEDGEMENTS}

We thank Ties Corten, Kasper Eising, Germán Waterdrinker, Manuel Ruiz and Francisco Fornieles for their help in setting up the enclosures, data collection and treatment implementation. Also we thank the local shepherd Javier Jimenez for assisting us with the goat grazing events. This study has been supported by a NWO-ALW Open Program Grant (Netherlands Science Foundation-Earth and Life Sciences, project number 820.01.020), the projects CASCADE (Grant Agreement 283068) funded by the Seventh Framework Programme FP7/2007e2013 and FEEDBACK (Grant \#CGL2011-30515-C02-01) and DRYEX (Grant \#CGL2014-59074-R) funded by the Spanish Ministry of Economy and Competitiveness.

\section{OPEN ACCESS}

This article is distributed under the terms of the Creative Commons Attribution 4.0 International License (http://creativecommons.org/licenses/by/4 $.0 /$ ), which permits unrestricted use, distribution, and reproduction in any medium, provided you give appropriate credit to the original author(s) and the source, provide a link to the Creative Commons license, and indicate if changes were made.

\section{REFERENCES}

Armas C, Pugnaire FI. 2005. Plant interactions govern population dynamics in a semi-arid plant community. J Ecol 93:97889.

Barroso FG, Alados CL, Boza J. 1995. Food selection by domestic goats in Mediterranean arid shrublands. J Arid Environ 31:205-17.

Bates D, Mächler M, Bolker B, Walker S. 2015. Fitting linear mixed-effects models using lme4. J Stat Softw 67(1):1-48.

Bertness MD, Callaway R. 1994. Positive interactions in communities. Trends Ecol Evol 9:191-3.

Bonanomi G, Incerti G, Mazzoleni S. 2011. Assessing occurrence, specificity, and mechanisms of plant facilitation in terrestrial ecosystems. Plant Ecol 212:1777-90.

Brooker RW, Callaghan TV. 1998. The balance between positive and negative plant interactions and its relationship to environmental gradients: a model. Oikos 81:196-207.

Brooker RW, Maestre FT, Callaway RM, Lortie CL, Cavieres LA, Kunstler G, Liancourt P, Tielbörger K, Travis JMJ, Anthelme F, Armas C, Coll L, Corcket E, Delzon S, Forey E, Kikvidze Z, Olofsson J, Pugnaire F, Quiroz CL, Saccone P, Schiffers K, Seifan M, Touzard B, Michalet R. 2008. Facilitation in plant communities: the past, the present, and the future. J Ecol 96:18-34. 
Brooker RW, Scott D, Palmer SCF, Swaine E. 2006. Transient facilitative effects of heather on Scots pine along a grazing disturbance gradient in Scottish moorland. J Ecol 94:637-45.

Bruno JF, Stachowicz JJ, Bertness MD. 2003. Inclusion of facilitation into ecological theory. Trends Ecol Evol 18:119-25.

Butterfield BJ, Bradford JB, Armas C, Prieto I, Pugnaire FI. 2016. Does the stress-gradient hypothesis hold water? Disentangling spatial and temporal variation in plant effects on soil moisture in dryland systems. Funct Ecol 30:10-19.

Callaway RM. 2007. Positive interactions and interdependence in plant communities. Dordrecht: Springer.

Callaway RM, Brooker RW, Choler P, Kikvidze Z, Lortie CJ, Michalet R, Paolini L, Pugnaire FI, Newingham B, Aschehoug ET, Armas C, Kikodze D, Cook BJ. 2002. Positive interactions among alpine plants increase with stress. Nature 417:844-8.

Callaway RM, Walker LR. 1997. Competition and facilitation: a synthetic approach to interactions in plant communities. Ecology 78:1958-65.

Calvete C, Pelayo E, Sampietro J. 2006. Habitat factors related to wild rabbit population trends after the initial impact of rabbit haemorrhagic disease. Wildl Res 33:467-74.

Castanho CT, Oliveira AA, Prado PIKL. 2015. Does extreme environmental severity promote plant facilitation? An experimental field test in a subtropical coastal dune. Oecologia 178:855-66

Filazzola A, Liczner AR, Westphal M, Lortie CJ. 2018. The effect of consumer pressure and abiotic stress on positive plant interactions are mediated by extreme climatic events. New Phytol 217:140-50.

Guerrero-Casado J, Carpio AJ, Tortosa FS. 2016. Recent negative trends of wild rabbit populations in southern Spain after the arrival of the new variant of the rabbit hemorrhagic disease virus RHDV2. Mamm Biol 81:361-4.

Gómez-Aparicio L. 2008. Spatial patterns of recruitment in Mediterranean plant species: linking the fate of seeds, seedlings and saplings in heterogeneous landscapes at different scales. J Ecol 96:1128-40.

Graff P, Aguiar MR. 2011. Testing the role of biotic stress in the stress gradient hypothesis. Processes and patterns in arid rangelands. Oikos 120:1023-30.

Graff P, Aguiar MR, Chaneton EJ. 2007. Shifts in positive and negative plant interactions along a grazing intensity gradient. Ecology 88:188-99.

Grant K, Kreyling J, Heilmeier H, Beierkuhnlein C, Jentsch A. 2014. Extreme weather events and plant-plant interactions: shifts between competition and facilitation among grassland species in the face of drought and heavy rainfall. Ecol Res 29:991-1001.

Haase P, Pugnaire FI, Clark SC, Incoll LD. 1996. Spatial patterns in a two-tiered semi-arid shrubland in southeastern Spain. J Veg Sci 7:527-34.

Hay ME. 1986. Associational plant defenses and the maintenance of species diversity: turning competitors into accomplices. Am Nat 128:617-41.

He Q, Bertness MD. 2014. Extreme stresses, niches, and positive species interactions along stress gradients. Ecology 95:143743.

He Q, Bertness MD, Altieri AH. 2013. Global shifts towards positive species interactions with increasing environmental stress. Ecol Lett 16:695-706.
Holmgren M, Scheffer M. 2010. Strong facilitation in mild environments: the stress gradient hypothesis revisited. J Ecol 98:1269-75.

Holthuijzen MF, Veblen KE. 2016. Grazing effects on precipitation-driven associations between sagebrush and perennial grasses. West North Am Nat 76(3):313-25.

Kéfi S, Rietkerk M, Alados CL, Pueyo Y, Papanastasis VP, ElAich A, De Ruiter PC. 2007. Spatial vegetation patterns and imminent desertification in Mediterranean arid ecosystems. Nature 449:213-17.

Le Bagousse-Pinguet Y, Maalouf J-P, Touzard B, Michalet R. 2014. Importance, but not intensity of plant interactions relates to species diversity under the interplay of stress and disturbance. Oikos 123:777-85.

Louthan AM, Doak DF, Goheen JR, Palmer TM, Pringle RM. 2014. Mechanisms of plant-plant interactions: concealment from herbivores is more important than abiotic-stress mediation in an African savannah. In: Proceedings of the Royal Society of London B: Biological Sciences. p 281.

Maestre FT, Callaway RM, Valladares F, Lortie CJ. 2009. Refining the stress-gradient hypothesis for competition and facilitation in plant communities. J Ecol 97:199-205.

Maestre FT, Cortina J. 2004. Do positive interactions increase with abiotic stress? A test from a semi-arid steppe. Proc R Soc B: Biol Sci 271:S331-3.

Mayor ÁG, Bautista S, Bellot J. 2009. Factors and interactions controlling infiltration, runoff, and soil loss at the microscale in a patchy Mediterranean semiarid landscape. Earth Surf Process Landf 34:1702-1 1.

McIntire EJB, Fajardo A. 2014. Facilitation as a ubiquitous driver of biodiversity. New Phytol 201:403-16.

Metz J, Tielbörger K. 2016. Spatial and temporal aridity gradients provide poor proxies for plant-plant interactions under climate change: a large-scale experiment. Funct Ecol 30:20-9.

Michalet R. 2007. Highlighting the multiple drivers of change in interactions along stress gradients. New Phytol 173:3-6.

Michalet R, Brooker RW, Cavieres LA, Kikvidze Z, Lortie CJ, Pugnaire FI, Valiente-Banuet A, Callaway RM. 2006. Do biotic interactions shape both sides of the humped-back model of species richness in plant communities? Ecol Lett 9:767-73.

Michalet R, Le Bagousse-Pinguet Y, Maalouf J-P, Lortie CJ. 2014. Two alternatives to the stress-gradient hypothesis at the edge of life: the collapse of facilitation and the switch from facilitation to competition. J Veg Sci 25:609-13.

Michalet R, Pugnaire FI. 2016. Facilitation in communities: underlying mechanisms, community and ecosystem implications. Funct Ecol 30:3-9.

Molina-Montenegro MA, Ricote-Martínez N, Muñoz-Ramírez C, Gómez-González S, Torres-Díaz C, Salgado-Luarte C, Gianoli E. 2013. Positive interactions between the lichen Usnea antarctica (Parmeliaceae) and the native flora in Maritime Antarctica. J Veg Sci 24:463-72.

Noumi Z, Chaieb M, Le Bagousse-Pinguet Y, Michalet R. 2016. The relative contribution of short-term versus long-term effects in shrub-understory species interactions under arid conditions. Oecologia 180:529-42.

Paine CET, Marthews TR, Vogt DR, Purves D, Rees M, Hector A, Turnbull LA. 2012. How to fit nonlinear plant growth models and calculate growth rates: an update for ecologists. Methods Ecol Evol 3:245-56. 
Perea R, Gil L. 2014. Shrubs facilitating seedling performance in ungulate-dominated systems: biotic versus abiotic mechanisms of plant facilitation. Eur J For Res 133:525-34.

Pugnaire FI, Armas C, Maestre FT. 2011. Positive plant interactions in the Iberian Southeast: mechanisms, environmental gradients, and ecosystem function. J Arid Environ 75:131020.

R Core Team 2015. R: A language and environment for statistical computing. Vienna: R Foundation for Statistical Computing.

Saccone P, Delzon S, Jean-Philippe P, Brun JJ, Michalet R. 2009. The role of biotic interactions in altering tree seedling responses to an extreme climatic event. J Veg Sci 20:403-14.

Saiz H, Alados CL. 2012. Changes in semi-arid plant species associations along a livestock grazing gradient. PLOS ONE 7:e40551.

Saiz H, Alados CL. 2011. Structure and spatial self-organization of semi-arid communities through plant-plant co-occurrence networks. Ecol Complex 8:184-91.

Smit C, Bakker ES, Apol MEF, Olff H. 2010. Effects of cattle and rabbit grazing on clonal expansion of spiny shrubs in woodpastures. Basic Appl Ecol 1 1:685-92.

Smit C, Rietkerk M, Wassen MJ. 2009. Inclusion of biotic stress (consumer pressure) alters predictions from the stress gradient hypothesis. J Ecol 97:1215-19.

Smit C, Vandenberghe C, Den Ouden J, Müller-Schärer H. 2007. Nurse plants, tree saplings and grazing pressure: changes in facilitation along a biotic environmental gradient. Oecologia 152:265-73.

Soliveres S, García-Palacios P, Castillo-Monroy AP, Maestre FT, Escudero A, Valladares F. 2011. Temporal dynamics of herbivory and water availability interactively modulate the out- come of a grass-shrub interaction in a semi-arid ecosystem. Oikos 120:710-19.

Soliveres S, Smit C, Maestre FT. 2015. Moving forward on facilitation research: response to changing environments and effects on the diversity, functioning and evolution of plant communities. Biol Rev 90:297-313.

Tálamo A, Barchuk A, Cardozo S, Trucco C, Marás G, Trigo C. 2015. Direct versus indirect facilitation (herbivore mediated) among woody plants in a semiarid Chaco forest: a spatial association approach. Austral Ecol 40:573-80.

Tielbörger K, Kadmon R. 2000. Temporal environmental variation tips the balance between facilitation and interference in desert plants. Ecology 81:1544-53.

Verwijmeren M, Rietkerk M, Bautista S, Mayor AG, Wassen MJ, Smit C. 2014. Drought and grazing combined: contrasting shifts in plant interactions at species pair and community level. J Arid Environ 111:53-60.

Verwijmeren M, Rietkerk M, Wassen MJ, Smit C. 2013. Interspecific facilitation and critical transitions in arid ecosystems. Oikos 122:341-7.

Virgós E, Cabezas-Díaz S, Malo A, Lozano J, López-Huertas D. 2003. Factors shaping European rabbit abundance in continuous and fragmented populations of central Spain. Acta Theriol 48:113-22.

Xu C, Van Nes EH, Holmgren M, Kéfi S, Scheffer M. 2015. Local facilitation may cause tipping points on a landscape level preceded by early-warning indicators. Am Nat 186:E81-90.

Zuur AF, Ieno EN, Walker NJ, Saveliev AA, Smith G. 2009. Mixed effects models and extensions in ecology with R. New York: Springer. 